\title{
O Controle do Uso do Solo para Proteção dos Mananciais
}

\author{
Antonio Claudio M. L. Moreira
}

O texto apresenta os efeitos urbanísticos da legislação de proteção dos mananciais da Regiāo Metropolitana de São Paulo. Considera esta legislação ineficaz para controle da expansão na borda da área urbanizada, porque, nāo leva em conta a prévia preparação para urbanização, e as características dos assentamentos populacionais nesta área.

Abstract

The paper presents the urbanistics effects of the legislation for water resources protection at São Paulo metropolitan area. Furthermore, the policy is ineffective to control the urban bonderings expansion, because it denies the previous preparation for urban use and the characteristics of populational settlement in this area.

Artigo elaborado com base na Dissertação de Mestrado "Política pública de proteção dos mananciais", apresentada em agosto de 1990.

Orientador: Prof. Dr. Celso Lamparelli. 


\section{Introdução}

A Grande São Paulo supre suas necessidades de água potável recorrendo aos recursos hídricos da Regiāo Metropolitana e importando água de bacias vizinhas.

Estes recursos são utilizados também para geração de energia elétrica, através da reversāo dos rios Tietê e Pinheiros, do bombeamento de suas águas para a represa Billings, e do lançamento destas águas, serra abaixo, para geração de energia elétrica em Cubatão.

Mas nem todos recursos hídricos da região são utilizáveis para abastecimento de água: mais da metade, $51 \%$, "encontram-se inutilizados para abastecimento de água e lazer devido, principalmente, aos elevados índices de poluição atingidos". (São Paulo, Assembléia Legislativa, 1975)

Os demais recursos hídricos encontram-se ameaçados pela expansão urbana da Grande São Paulo. Os corpos de água são alterados: a quantidade de matéria estranha é maior do que sua capacidade de assimilação. O ciclo hidrológico é alterado: a remoção da cobertura vegetal natural - a Mata Atlântica - reduz a evapotranspiração e por via de conseqüência a umidade presente no ar; a impermeabilização do solo reduz a infiltração, e consequentemente o volume de água armazenado no subsolo; a impermeabilização da superfície e a canalização dos cursos de água aumenta a velocidade de escoamento e afasta as águas da regiāo.

Este quadro de uso múltiplo dos recursos hídricos e de expansão urbana na direção dos mananciais determinaram a política pública de proteção dos mananciais da Região Metropolitana de São Paulo.

\section{A Disputa pelos Recursos Hídricos}

A Região Metropolitana de São Paulo contém em seu território as cabeceiras dos rios Tietê, Paraíba do Sul e Juquiá. Destas a bacia do Alto Tietê é a principal; compreende o rio Tietê e seus afluentes, desde suas cabeceiras até a barragem de Pirapora. Nesta bacia, $20 \%$ dos recursos hídricos são utilizados para abastecimento de água.

Desde 1975 (governo Paulo Egídio) foram implementadas políticas de proteçāo dos recursos hídricos da Região Metropolitana de São Paulo: foi instaurado o controle de uso e ocupação do solo nas vertentes tributárias dos mananciais metropolitanos - a legislação de proteção dos mananciais; foram ativadas as obras do sistema de tratamento de esgotos de São Paulo, o controvertido SANEGRAN; foram realizadas obras de separação entre a represa Billings e seu braço do rio Grande que abastece a região do $A B C$; recentemente, disposição transitória da Constituição Estadual estabelece prazo para cessar o recalque de substâncias poluentes para a represa Billings.

Mas até 1982 (governo Montoro), os recursos hídricos estavam predominantemente comprometidos com a produçāo de energia elétrica: $87 \mathrm{~m}^{3} /$ segundo seguiam para as usinas geradoras de energia elétrica da Eletropaulo em Cubatão, e $3 \mathrm{~m}^{3} /$ segundo seguiam Tietê abaixo (São Paulo, Assembléia Legislativa, 1975). A partir de 1982, foram implementadas políticas de gestão dos recursos hídricos da bacia do Alto Tietê, principalmente para controle de cheias e de poluição. Preliminarmente, toda vazão dos rios Tietê e Pinheiros, e por conseqüência toda carga poluidora desses rios, foi descarregada sobre o Médio Tietê (operação saneamento) para reduzir a poluição da represa 
Billings. Após, essa vazão média, e a correspondente carga poluidora desses rios, foi dividida em partes iguais entre as represas Billings e Pirapora (operação balanceada). No período de cheias é acionada toda capacidade de bombeamento para a Billings e liberada toda capacidade de vazão para o Médio Tietê (operação enchente). Recentemente (governo Quércia), no período de estiagem, toda vazāo do rio Tietê a montante do rio Pinheiros é desviada através do rio Pinheiros para a represa Billings, a fim de facilitar as obras de aprofundamento da calha do rio Tietê.

Entretanto, essas políticas de uso múltiplo dos recursos hídricos da bacia do Alto Tietê não são compatíveis entre si. Do lado do abastecimento de água, a legislação dos mananciais pretende proteger todos os recursos hídricos utilizáveis para abastecimento da metrópole paulistana, visando destiná-los ao abastecimento de água. Do lado da energia elétrica a política pública preservava até o advento da nova Constituição paulista - o recalque das águas poluídas do rio Pinheiros para a represa Billings, um dos mananciais protegidos por lei. Do lado do tratamento de esgotos a política pública prévia - até o advento da nova Constituição paulista - o despejo de efluentes de estação de tratamento de esgotos, da regiāo do $A B C$ sobre a represa Billings, um dos mananciais protegidos por lei.

Esta é a questão dos mananciais metropolitanos de São Paulo: a disputa entre abastecimento de água e energia elétrica (outros usuários são pouco relevantes em face desses) pelos recursos hídricos da bacia do Alto Tietê.

A represa Billings condensa esta questão: faz parte do sistema de geração de energia elétrica da Eletropaulo em Cubatão, como reservatório receptor das águas - poluídas - dos rios Pinheiros e Tietê; é recurso hídrico protegido pela legislação dos mananciais; deverá receber o efluente de estação de tratamento de esgotos da regiāo do ABC.

Enquanto persistir o bombeamento do rio Pinheiros para a Billings - proibido pela Constituição Estadual a partir de outubro de 1992 - a carga poluidora despejada neste reservatório continuará elevada, inviabilizando sua utilização como manancial abastecedor de água da Grande São Paulo. E o interesse por este bombeamento não é pequeno! O sistema de alimentaçāo de energia elétrica da Regiāo Metropolitana, cuja capacidade de transmissão encontra-se praticamente saturada, depende da geração de energia elétrica em Cubatão, e por conseqüência depende do bombeamento das águas poluídas dos rios Pinheiros e Tietê para a represa Billings.

E a possibilidade de um bombeamento de águas não poluídas é remota! A médio prazo o projeto de tratamento de esgotos da Grande São Paulo - o SANEGRAN, limitado ao tratamento de $7,2 \mathrm{~m}^{3} / \mathrm{segundo}$, apenas evitará o agravamento da poluição dos rios Pinheiros e Tietê. Mesmo em sua capacidade máxima, estes rios continuarão poluídos, pois o volume de água distribuído, e conseqüentemente de esgotos gerados, ainda é maior do que a capacidade máxima do tronco interceptor.

\section{A Expansão Urbana na Direção dos Mananciais}

A cidade de São Paulo extravasou os limites do município. Veio a compor o que - Padre Lebret denominou Grande São Paulo (SAGMACS, 1958), e que a Lei Federal institucionalizou como Região Metropolitana de São Paulo. Seu crescimento populacional foi intenso: atingiu 15 milhões de habitantes em 1985 (S. Paulo, Estado, 1985), e ainda continua a crescer. 
Desde 1975, os estudos para a Região Metropolitana, o Diagnóstico 75 (César et al., 1975), alertavam para a tendência da expansão urbana na direção dos mananciais. Com base neste estudo, a exposição de motivos do projeto de lei 241/75 apresentava um negro prognóstico desta expansão urbana: "a curto prazo será perdido para o abastecimento público o Baixo Cotia ... e na seqüência, o Guarapiranga e a Billings que totalizam uma disponibilidade de $24 \mathrm{~m}^{3} / \mathrm{se}$ gundo" (São Paulo, Assembléia Legislativa, 1975)

Essa expansão urbana de fato ocorreu, como demonstram os estudos de Sócrates, Grostein e Tanaka que comparam a extensão da mancha urbana de São Paulo nos anos de 1972 e 1983; e como demonstra o mapa elaborado pela Empresa Metropolitana de Planejamento da Grande São Paulo - EMPLASA, sob o título de Expansão da Área Urbanizada na Região Metropolitana de São Paulo.

Essa expansão urbana foi localizada principalmente no entorno da área já urbanizada. Atinge, na área de proteçāo dos mananciais, o entorno da represa Guarapiranga e o vale do rio Juquerí.

Mas a proporção da área de proteção dos mananciais ocupada pela urbanização ainda é muito pequena em relação à extensāo da área protegida - quase $55 \%$ da Região Metropolitana.

\section{A Legislação de Proteção dos Mananciais}

Diante da disputa pelos recursos hídricos da Regiāo Metropolitana, e da expansão urbana na direção dos mananciais, o governo do estado de São Paulo optou pela proteção dos mananciais.

$\mathrm{Na}$ federação brasileira os estados nāo decidem sobre a destinação dos recursos hídricos, que é competência privativa da União (Constituição Federal, Art. 21). Mas, os estados tem competência para legislar sobre saúde inclusive a proteção dos recursos hídricos (Constituição Federal, Art. 23) e mais recentemente sobre proteção de meio ambiente (Constituição Federal, Art. 24).

As leis estaduais $898 / 75,1.172 / 76,2.177 / 77$ e $3.286 / 82$, regulamentadas pelos decretos estaduais 9.717/77. 12.219/78 e 15.037/80, e dispositivos da Constituição Estadual de 1989 concretizam a proteção aos mananciais metropolitanos de São Paulo.

A lei 898/75 identifica os recursos hídricos protegidos e define seu instrumento: - controle "dos projetos de arruamentos, loteamentos, edificaçōes e obras, bem assim a prática de atividades agropecuárias, comerciais, industriais e recreativas" (Art. 3․, parágrafo único), nas bacias de drenagem dos mananciais protegidos (Art. 3ํ, caput), mediante restrições a serem estabelecidas em lei (Art. 11).

A lei 1.172/76, modificada pela leis $2.177 / 79$ e $3.286 / 82$, define algumas destas restrições: a delimitação da área de proteção dos mananciais e das áreas de maior e menor restrição, a imposição de normas relativas ao uso e à ocupação do solo, ao parcelamento e arruamento, à impermeabilização do solo, ao desmatamento, à coleta e disposição de esgotos e resíduos sólidos.

Os decretos 9.714/77 e 12.219/78 definem as atribuições dos agentes estaduais gestores destas normas (Secretaria da Habitação e Desenvolvimento Urbano, Empresa Metropolitana de Planejamento da Grande São Paulo - 
EMPLASA, Companhia Estadual de Tecnologia de Saneamento Básico e Defesa do Meio Ambiente - CETESB, Secretaria do Meio Ambiente), e autorizam convênios, com os municípios da Regiāo Metropolitana, para exame, adaptação e aprovação de projetos de residências unifamiliares na área de proteção dos mananciais.

A nova Constituição do Estado de São Paulo proíbe o lançamento de efluentes de esgotos em qualquer corpo de água, sem o devido tratamento (Art. 208), e estabelece o prazo de 3 anos para o poder público impedir o bombeamento de águas servidas, dejetos e outras substâncias poluentes para a represa Billings (Art. 46 das disposições transitórias)

\section{A Politica de Proteção dos Mananciais}

De um ponto de vista estritamente técnico, a escassez de recursos hídricos, bem como os efeitos da urbanização da bacia de drenagem dos mananciais protegidos, e ainda a disputa pelos recursos hídricos da bacia do Alto Tietê, poderiam ser solucionados.

Para tanto, basta mobilizar os recursos da sociedade e do poder público para despoluição dos recursos hídricos da bacia do Alto Tietê, para implantaçāo de infra-estrutura urbana - especialmente sanitária - nas áreas já ocupadas pela expansão urbana, e para substituição das fontes de energia elétrica que abastecem a Grande São Paulo.

Entretanto, a questāo nāo é meramente técnica. As instalaçōes dos sistemas de abastecimento de água, de afastamento de esgotos e de geração energética, são meios de consumo coletivo, isto é, são "suportes materiais de atividades destinadas à reprodução ampliada de uma força de trabalho social" (Lojkine, 1972, p. 3) E como meios de consumo coletivo, que integram o meio urbano, essas instalações "estão no centro da contradição atual entre as novas exigências do progresso técnico - essencialmente em matéria de formação ampliada das forças produtivas humanas - $e$ as leis de acumulação do capital" (Lojkine, 1981, p. 121) E nessa condição participam da divisão social peculiar à cidade capitalista.

A política pública condensa as relaçōes de forças de grupos em conflito ou contradição com a participação do Estado. No caso, a política pública de proteção dos mananciais, nāo resolve a disputa pelos recursos hídricos da bacia do Alto Tietê, mas interfere nessa disputa. De fato, essa política pública não decide que parte dos recursos hídricos em questão serão destinados ao abastecimento de água, à diluição de esgotos, à geração de energia elétrica, e a outros usos. Mas essa política pública evita que os mananciais sejam poluídos, e assim garante a presença do sistema de abastecimento de água como disputante desses recursos hídricos.

A política pública de proteção dos mananciais expressa a decisão do Estado de escolher, como objeto de intervenção, a preservação da qualidade das águas, independentemente de seu uso. Expressa, também, a decisão do Estado de definir como partes em conflito - os usuários dos recursos hídricos destináveis ao abastecimento de água (Sabesp), em confronto com os usuários das bacias de drenagem adjacentes; e mais recentemente, os interessados no bombeamento de águas poluidas para a represa Billings, em confronto com os interessados na qualidade das águas. 


\section{A dimensão planificadora da proteção dos mananciais}

O governo estadual materializou a política pública de proteção dos mananciais, pela disciplina das atividades humanas nas bacias de drenagem dos mananciais protegidos, e mais especificamente pelo controle do uso e da ocupação do solo, e pelo controle das condições de coleta, transporte e destino final de esgotos e resíduos sólidos. Apenas recentemente, a constituinte estadual opta também pelo controle do bombeamento de águas poluídas para a Billings.

Outras intervenções para proteção dos mananciais foram desconsideradas. Outras possibilidades de disciplina das atividades humanas na bacia de drenagem dos mananciais protegidos foram desconsideradas. Mesmo a tradicional desapropriação da bacia contribuinte foi considerada ultrapassada, economicamente inviável, e descartada - exceto em casos excepcionais.

Assim, a política pública de proteção dos mananciais, reduziu-se a uma política pública de disciplina das atividades de terceiros nas bacias de drenagem dos mananciais protegidos; e a uma política de controle do bombeamento para a represa Billings.

\section{A dimensão operacional da proteção dos mananciais}

O instrumental de implantação da política pública de proteção dos mananciais revela uma concepção jurisdicista de Estado. O instrumento de controle da qualidade das águas definido pela legislação de proteção dos mananciais é a polícia administrativa do uso do solo e da coleta, transporte e disposiçāo de resíduos sólidos. Por sua vez, o instrumento de controle da qualidade das águas, determinado pela Constituiçāo Estadual, é polícia administrativa do bombeamento de dejetos para a Billings. Ambos, são instrumentos legais reguladores de atividades de terceiros: proprietários e usuários da área de proteçāo dos mananciais; operadores do sistema de recalque do rio Pinheiros para a Billings (Eletropaulo); e operadores da futura estação de tratamento de esgotos da região do $A B C$ (Sabesp), com peculiaridade desses últimos integrarem o aparelho de Estado.

Essa concepção jurisdicista trata a sociedade como se todos os seus membros fossem iguais. Assim ignora (ou faz vistas grossas) à derrogação da lei, freqüentemente praticada pelos produtores de parcelamentos irregulares. Ou seja, ignora o acordo tácito entre produtores de loteamentos clandestinos, agentes públicos responsáveis pela sua fiscalização, e compradores dos lotes, de não denunciar as ilegalidades, na expectativa da futura anistia das irregularidades do parcelamento. Tal acordo ocorre pela ascendência das classes dominantes sobre o aparelho de Estado, e pelo interesse do poder público de se legitimar junto às classes subalternas.

Essa concepção jurisdicista ignora também (ou faz vista grossa também) a derrogação da lei, freqüentemente praticada pela população mais pobre na produção de suas edificaçōes. Ou seja, ignora o acordo tácito entre produtores de edificaçōes e agentes públicos responsáveis pela sua fiscalizaçāo, de não denunciar a desobediência à lei, na expectativa da futura anistia das irregularidades.

Por outro lado o uso desse instrumental apresenta limitaçōes. Há limitaçōes peculiares ao exercício do poder de polícia administrativa, a saber: a necessidade de uma fiscalização intensa e permanente, sempre sujeita à corrupção; a constatação tardia das situações irregulares, quando os danos são dificilmente reparáveis; a ineficácia da notificação e da sanção administrativas para sustar procedimentos irregulares; a morosidade de procedimentos judiciais que obri- 
gam os infratores a sustar procedimentos irregulares e a reparar danos ao meio ambiente.

Há ainda limitações peculiares à formação social, a saber: a capacidade de derrogação da lei, peculiar aos proprietários imobiliários das classes dominantes; e a impossibilidade de controle das condições de uso e ocupação do solo da população mais pobre, habituada a viver na clandestinidade.

\section{O efeito sobre a expansão urbana}

O efeito do discurso e do instrumental de disciplina do uso do solo na área de proteção dos mananciais é aparentemente contraditório. De um lado, houve expansão urbana da Grande São Paulo na área protegida, predominantemente no entorno da represa Guarapiranga, e no vale do rio Juquerí. De outro lado, a extensão da área de proteção dos mananciais ocupada pela urbanização, é muito pequena em relação à extensão total da área protegida.

Olhando a questão do lado da pequena proporção da área protegida, que foi ocupada pela urbanização, é possível afirmar que a legislação de proteção dos mananciais atingiu seu objetivo de conter a expansão urbana na área protegida. Entretanto, é preciso considerar que no periodo pós-legislação de mananciais, houve desaceleração do crescimento demográfico da Grande São Paulo, assim como a desaceleração do crescimento econômico pós "milagre brasileiro", aos quais corresponde a desaceleração do crescimento da área urbanizada e dos negócios imobiliários. É preciso considerar também que o crescimento urbano dos 15 anos pós-legislação de proteção dos mananciais é muito pequeno perante a extensão da área de proteção dos mananciais $55 \%$ da Grande São Paulo.

Nessas condições, a contenção da expansão da mancha urbana na direção dos mananciais é atribuivel, principalmente, à desaceleração do crescimento da Grande São Paulo e, subsidiariamente, à legislação de proteção dos mananciais, já que essa legislação não foi eficaz nas áreas de grande pressão para urbanização - o entorno da área urbanizada.

Desfeita assim a aparente contradição, é possivel afirmar que a legislação de proteção dos mananciais foi insuficiente para conter a expansão urbana na área protegida. Parte da área protegida já se encontrava preparada para a urbanização, por ocasião da legislação de proteção dos mananciais. Trata-se de área com menor qualificação urbana devido à precariedade dos sistemas públicos de água, esgotos, vias e transportes. Essa área foi ocupada pela população de baixa renda.

A produção de áreas diferenciadas pela qualificação urbana, é, segundo Castells, a "estratificação urbana correspondendo ao sistema de estratificação social" (1982, p. 210) É também, segundo Lojkine, a "expressão da divisão material e intelectual do trabalho, que resume a contradição entre a exigência do desenvolvimento do trabalho e a acumulação capitalista, e que tende a restringir ao máximo o desenvolvimento do trabalho" (Lojkine, 1981, p. 321)

Essa segregação urbana, segundo Lojkine, é operada pela renda fundiária urbana (1981, p. 166), que engendra a distribuição desigual das habitações, o subequipamento dos bairros dos trabalhadores e a crise dos transportes coletivos (Lojkine, 1981, p. 222), e que destina às áreas de menor renda diferencial aos guetos urbanos (Harvey, 1980) e, pelo menos em Sāo Paulo, às classes operárias. (Bonduki e Rolnik, 1979) 
Assim, considerando a preparação (para urbanização) da área contígua à área urbanizada, a baixa qualificação dessa área, e a destinação das áreas menos qualificadas à população pobre, era inevitável sua ocupaçāo pela população de baixa renda, já que sua menor qualificação afastava outros estratos sociais.

A ocupação dessa área pela população mais pobre é predatória para os mananciais, pela carência generalizada de equipamentos e serviços urbanos - é território de baixa qualificação urbana; pelas dimensōes reduzidas dos lotes - para serem acessiveis à população de baixa renda; e pela impossibilidade dessa população autofinanciar as condiçōes de preservação do ambiente.

\section{O efeito sobre a área urbanizada}

O efeito da política pública de proteção dos mananciais, sobre a área urbanizada foi transferir os encargos da proteção aos proprietários e usuários da área protegida.

De fato, a disciplina de uso do solo, predominantemente com restriçōes à urbanização e à edificação, reduz as possibilidades de aproveitamento das propriedades urbanizáveis e urbanizadas, impedindo a valorizaçāo e frustando expectativas de lucro imobiliário.

O grau de conflito entre os interessados na proteção dos mananciais e os proprietários e usuários da área preservada, é determinado pela intensidade da desvalorizaçāo imobiliária, que por sua vez é decorrência da intensidade das restrições impostas ao uso e à ocupação do solo. Ou seja, o conflito na proteção dos mananciais não é apenas uma decorrência da proteção, mas é também decorrência do modo de proteção adotado.

Nas áreas de maior restrição, as áreas de primeira categoria, que correspondem às faixas marginais aos corpos de água protegidos, às matas e todas as formas de vegetação primitiva, e aos declives superiores a $60 \%$, a política pública de proteção dos mananciais pretende impedir o uso urbano e obrigar seus proprietários a preservar a vegetaçāo nelas existente sem qualquer utilidade para eles. Seu efeito é a desocupação das áreas de primeira categoria, expondo-as às invasões, bem como a destruição das matas, na expectativa de descaracterizar a restrição, apesar das bonificações pela sua preservação, pelo efeito irrisório das bonificações.

Nas áreas de menor restrição, as áreas de categoria classe "A" que correspondem às áreas já urbanizadas por ocasiāo da promulgaçāo da legislação dos mananciais, a política pública de proteção dos mananciais estabelece restriçōes urbanísticas predominantemente compativeis com os padrōes da periferia. Seu efeito é a ocupação dessas áreas, segundo padrōes de ocupação correntes na periferia metropolitana, aceitos pela legislação de proteçāo dos mananciais.

Nas demais áreas, áreas de segunda categoria classes " $\mathrm{B}$ " e " $\mathrm{C}$ " que correspondem à maior parte da área protegida, a política pública de proteção dos mananciais estabelece restrições urbanísticas muito exigentes relativamente aos padrōes da área urbanizada. O efeito do discurso e do instrumental foi o descontrole da expansão urbana das áreas de segunda categoria classes "B" e " $C$ " nas imediaçōes das áreas já urbanizadas — inclusive o entorno dos mananciais protegidos, e a dos loteamentos preexistentes à legislação de proteção dos mananciais. 


\section{Conclusão}

O discurso da proteção da qualidade das águas através da disciplina das atividades humanas nas áreas adjacentes aos mananciais protegidos, e seu instrumental de desqualificação dessas áreas para fins urbanos, não foram suficientes para conter a expansão urbana no entorno da área já urbanizada.

Isto ocorreu, principalmente, pelo instrumental de intervenção desconsiderar a prévia preparação para urbanização da faixa contígua à área urbanizada, sua baixa qualificação, e sua destinação à população de baixa renda.

Nesse contexto não é simplesmente a atividade humana que determina "o regime quantitativo e qualitativo da água drenada e, por conseqüência quantidade e qualidade da água do manancial" (São Paulo, Assembléia Legislativa, 1976), como pretende o discurso da proteçāo dos mananciais, mas, principalmente, a forma como essa atividade humana ocorre.

Também não é a urbanização que conduzirá "a inutilização das disponibilidades restantes e comprometerá os esquemas de reversão previstos" (São Paulo, Assembléia Legislativa, 1975), como pretende o discurso da proteção dos mananciais, mas, principalmente a forma com que essa urbanização ocorre.

Assim, não é qualquer atividade humana que depreda o meio ambiente, nem é qualquer urbanização a origem dos problemas de meio ambiente. É preciso referenciar os danos causados ao meio ambiente, é preciso "articulá-los com os diferentes processos da estrutura social" que os produzem. (Castells, 1983, p. 236)

É preciso reconhecer que diferentes formas de urbanização têm diferente impacto sobre o meio ambiente, e que essas formas são determinadas pela qualificação urbana das áreas.

Ou seja, se a sociedade e o poder público provessem áreas melhor qualificadas para assentamento da população mais pobre; e provessem melhor qualificação das áreas urbanas preservadas, teriamos muito menos a temer em termos de impacto sobre o meio ambiente e de poluição dos mananciais.

\section{Bibliografia}

BONDUKI, Nabil, ROLNIK, Raquel. Periferia da Grande São Paulo. Reprodução do espaço como expediente de reprodução da força de trabalho. In: MARICATO. H. A produção capitalista da casa (e da cidade) no Brasil. São Paulo: Alfa-Omega, 1979.

CASTELLS. Manuel. A questão urbana. Rio de Janeiro: Paz e Terra, 1983.

CÉSAR, Roberto Cerqueira et al. Regiảo Metropolitana de São Paulo: Diagnóstico 75. São Paulo, 1975, mimeo.

HARVEY. David. A Justiça social e a cidade. São Paulo: Hugitec, 1980.

LOJKINE, Jean. Contribution à une théorie Marxiste de l'urbanisation Capitaliste. In: Cahiers Internationaux de Sociologie. Paris: PUF L11 (1972).

O Estado capitalista e a questão urbana. Sảo Paulo: Martins Fontes, 1981.

SAGMACS, Sociedade de Análises Gráficas e Mecanográficas Aplicadas a Complexos Sociais. Aglomeração metropolitana. Sảo Paulo, 1958.

SĀO PAULO (Assembléia Legislativa). Projeto de lei 241/75. Sāo Paulo, 1975

Projeto de lei 314/76. São Paulo, 1976. 
SẢO PAULO (Estado). Secretaria dos Negócios Metropolitanos. Empresa Metropolitana de Planejamento da Grande São Paulo. Plano metropolitano de desenvolvimento. São Paulo, 1985.

SÓCRATES, Jodete Rios, GROSTEIN, Marta Dora, TANAKA, Marta Soban. A cidade invade as águas: qual a questāo dos mananciais? Sinopses. São Paulo: FAUUSP, 1985, Edição especial. 